\title{
Resistance to experimental autoimmune encephalomyelitis development in Lewis rats from a conventional animal facility
}

\author{
Sofia Fernanda Gonçalves Zorzella, Juliana Seger, Douglas Rodrigues Martins, \\ Ana Claudia Pelizon, Alexandrina Sartori ${ }^{+}$
}

Instituto de Biociências, Departamento de Microbiologia e Imunologia, Universidade Estadual Paulista, Distrito de Rubião Júnior s/n, 18618-000 Botucatu, SP, Brasil

Experimental autoimmune encephalomyelitis (EAE) is an inflammatory disease of the brain and spinal cord that is mediated by $\mathrm{CD}^{+} \mathrm{T}$ lymphocytes specific to myelin components. In this study we compared development of EAE in Lewis rats from two colonies, one kept in pathogen-free conditions (CEMIB colony) and the other (Botucatu colony) kept in a conventional animal facility. Female Lewis rats were immunized with $100 \mu \mathrm{l}$ of an emulsion containing $50 \mu \mathrm{g}$ of myelin, associated with incomplete Freund's adjuvant plus Mycobacterium butyricum. Animals were daily evaluated for clinical score and weight. CEMIB colony presented high EAE incidence with clinical scores that varied from three to four along with significant weight losses. A variable disease incidence was observed in the Botucatu colony with clinical scores not higher than one and no weight loss. Immunological and histopathological characteristics were also compared after 20 days of immunization. Significant amounts of IFN- $\gamma, T N F-\alpha$ and IL-10 were induced by myelin in cultures from CEMIB animals but not from the Botucatu colony. Significantly higher levels of anti-myelin $\operatorname{Ig} G_{1}$ were detected in the CEMIB colony. Clear histopathological differences were also found. Cervical spinal cord sections from CEMIB animals showed typical perivascular inflammatory foci whereas samples from the Botucatu colony showed a scanty inflammatory infiltration. Helminths were found in animals from Botucatu colony but not, as expected, in the CEMIB pathogen-free animals. As the animals maintained in a conventional animal facility developed a very discrete clinical, and histopathological EAE in comparison to the rats kept in pathogen-free conditions, we believe that environmental factors such as intestinal parasites could underlie this resistance to EAE development, supporting the applicability of the hygiene hypothesis to EAE.

Key words: experimental autoimmune encephalomyelitis - rats inbred Lewis - cytokines

The extraordinary susceptibility of the Lewis rat to a large number of different inducible tissue-specific autoimmune diseases has made it a much-studied experimental model in the field of autoimmunity. Experimental autoimmune encephalomyelitis (EAE) is a Th1 mediated inflammatory paralytic disease of the central nervous system (CNS), which serves as a model of human demyelinating diseases of the CNS such as multiple sclerosis (MS) (Swanborg 1975, Gold et al. 2006). The autoreactive $\mathrm{CD}^{+} \mathrm{T}$ cells cross the blood-brain barrier and secrete the pro-inflammatory cytokines IFN- $\gamma$ and TNF- $\alpha$ in response to epitopes present in CNS proteins, including myelin basic protein (MBP), proteolipid protein and myelin oligodendrocyte glycoprotein. EAE can be actively induced in the Lewis rat by subcutaneous injection of MBP in Complete Freund's Adjuvant (CFA), or passively by the adoptive transfer of in vitro MBPrestimulated $\mathrm{T}$ cells from MBP-sensitized syngeneic donor rats (Swanborg 1988). The clinical course of MBP-induced EAE in the Lewis rat is an acute ascending paralysis, that is monophasic and self-limiting, making

Financial support: CNPq, FAPESP.

${ }^{+}$Corresponding author: sartori@ibb.unesp.br

Received 3 July 2007

Accepted 13 November 2007 it an ideal model to study the regulatory events that lead to recovery from autoimmune diseases (Swanborg 1995). MS and EAE development are clearly affected by different factors as gender (Papenfuss et al. 2004), age (Ditamo et al. 2005), and also by genetic and environmental conditions (Sotgiu et al. 2004). The hygiene hypothesis has been proposed to explain the increased incidence of autoimmune diseases and allergy in areas of the world with improved health care and sanitation. This hypothesis proposes that the lack of intense infections in industrialized countries owing to improved hygiene, vaccination and use of antibiotics alters the immune system in a way that it responds inappropriately. Imbalance of Th1 and Th2 responses and lack of regulatory T-cell populations are two of many proposed potential mechanisms for immune failures such as autoimmunity and allergy (Sewell et al. 2002). During standardization of EAE we initially used a Lewis rat colony established in the Department of Microbiology and Immunology (UNESP, Botucatu). In spite of exhaustive trials, only very discrete clinical scores were observed. As our animal facility is conventional and Lewis rats are described as highly susceptible to EAE development (Swanborg 2001), we attributed this resistance to differences in sanitary barrier conditions. To test this possibility we compared EAE development in two colonies of Lewis rats, one raised and kept in pathogen-free conditions (CEMIB colony) and the other in a conventional animal facility (Botucatu colony). 


\section{MATERIALS AND METHODS}

Animals - Female Lewis rats (4-6 weeks old) were obtained from two sources: CEMIB/UNICAMP and UNESP/Botucatu, and named CEMIB and Botucatu colonies, respectively. These two colonies are from different origins. The Botucatu colony was established with rats from the laboratory of Clinical and Experimental Allergy and Immunology, Faculty of Medicine, São Paulo University, originally obtained from MA Bioproducts (Walkerville, MD, USA), while the CEMIB colony was established with pairs purchased from Harlan Sprague Dowley (Indianapolis, IN, USA). The animals were fed with a standard granulated food and water ad libitum. Food and water were sterilized. Animals were manipulated in compliance with the ethical guidelines adopted by Colégio Brasileiro de Experimentação Animal, being the experimental protocol approved by the local Ethics Committee (protocol 458).

Induction and scoring of EAE - The main immunization protocol used for both colonies was inoculation of $100 \mu \mathrm{l}$ of an emulsion containing $50 \mu \mathrm{g}$ of MBP (Sigma Chemical Co, St. Louis, MO, USA) associated with $50 \mu \mathrm{l}$ of Incomplete Freund's Adjuvant (Difco Laboratories, Detroit, MI, USA) plus $5 \mathrm{mg} / \mathrm{ml}$ of Mycobacterium butyricum (Difco Laboratories, Detroit, MI, USA), in the left footpad. Larger amounts of myelin or Freund's adjuvant or subcutaneous route were also tried. Non immunized animals from both colonies were used as control groups. Weight variation and clinical scores were daily recorded. Signs of disease were graded as 0 (zero): no disease; 1: loss of tonicity of the distal portion at the tail; 2: total loss of tail tonicity; 3 : hind limb weakness (partial paralysis); 4: complete hind limb paralysis and urinary incontinence, and 5: moribund.

Histopathological analysis - The histological analysis of cervical spinal cord sections was performed on day 20 following immunization. Fragments from the cervical spinal cord were removed, fixed in $10 \%$ formalin and embedded in paraffin. Five micrometer sections were cut and stained with hematoxylin and eosin and examined with an Olympus microscope.

Anti-myelin antibody levels - Serum samples were collected on day 20 following immunization and tested by enzyme linked immunosorbent assay (ELISA) for the presence of antibodies against MBP. Briefly, plates were coated with $5 \mu \mathrm{g} / \mathrm{ml}$ of antigen in coating solution $\left(\mathrm{Na}_{2} \mathrm{CO}_{3} / \mathrm{NaHCO}_{3}, \mathrm{pH} 9,6\right)$ overnight at $4^{\circ} \mathrm{C}$. Non-specific antibody binding was blocked by incubation with $0,05 \%$ Tween $20,10 \%$ fetal calf serum (FCS) in phosphate buffered saline (PBS, $200 \mu \mathrm{l}$ per well) for $1 \mathrm{~h}$ at $37^{\circ} \mathrm{C}$. Subsequently the plates were incubated overnight at $4{ }^{\circ} \mathrm{C}$ with dilutions of serum from control and immunized rats. For the detection of specific serum $\mathrm{IgG}_{1}$ and $\operatorname{IgG}_{2 b}$, the plates were incubated with biotinylated mouse anti-rat antibodies (Oxford Biotechnology). Plates were then incubated for $30 \mathrm{~min}$ at room temperature with Strept $\mathrm{AB}$ (kit from Dako, Carpinteria), and revealed by adding $\mathrm{H}_{2} \mathrm{O}_{2}$ with o-phenylenediamine (OPD) (Sigma, St. Louis, MO, USA). Color development was stopped with $\mathrm{H}_{2} \mathrm{SO}_{4}$ and optical density was measured at $492 \mathrm{~nm}$.
$I F N-\gamma, T N F-\alpha$ and IL-10 production - Normal and immunized rats were sacrificed 20 days after immunization. Lymph node (popliteal + inguinal) cells were collected, and adjusted to $2.5 \times 10^{6} / \mathrm{ml}$. Cells were cultured in complete RPMI medium (RPMI supplemented with $5 \%$ FCS, $20 \mathrm{mM}$ glutamine and $40 \mathrm{IU} / \mathrm{ml}$ of gentamicin), in the presence of $10 \mu \mathrm{g} / \mathrm{ml}$ of myelin or $5 \mu \mathrm{g} / \mathrm{ml}$ of Concanavalin A (ConA, Sigma, St. Louis, MO, USA). Cytokine levels in culture supernatants were evaluated $48 \mathrm{~h}$ later by ELISA according to manufacturer instructions (R\&D Systems, Minneapolis, MN, USA). 96 well plates (NUNC) were coated with capture antibodies for IFN- $\gamma$ (DY 585), TNF- $\alpha$ (DY 510) or IL-10 (DY 522) diluted in PBS at $2 \mu \mathrm{g} / \mathrm{ml}, 4 \mu \mathrm{g} / \mathrm{ml}$ and $4 \mu \mathrm{g} / \mathrm{ml}$, respectively. Plates were incubated overnight and then blocked during $2 \mathrm{~h}$ with $1 \%$ albumin in PBS. Standard rat cytokines and culture supernatants were added and the plates incubated for $2 \mathrm{~h}$. Biotinylated anti-IFN- $\gamma$, antiTNF- $\alpha$ and anti-IL-10 antibodies were added (150, 100 and $100 \mathrm{ng} / \mathrm{ml}$, respectively), and plates were incubated during $2 \mathrm{~h}$ at room temperature. Then, plates were incubated at room temperature for $30 \mathrm{~min}$ with Streptavidin and then revealed by adding $\mathrm{H}_{2} \mathrm{O}_{2}+\mathrm{OPD}$. Color development was stopped with $\mathrm{H}_{2} \mathrm{SO}_{4}$, and optical density was measured at $492 \mathrm{~nm}$. Sensitivity of ELISA for IFN- $\gamma$, TNF- $\alpha$ and IL-10 were 20,30 and $30 \mathrm{pg} / \mathrm{ml}$, respectively.

Statistical analysis - Statistical analysis was performed using Minitab Version 1996 (Minitab, State College, PA, USA). One-way ANOVA and the Tukey test were used to compare the clinical scores, the production of anti-myelin antibodies and the cytokine levels $(p<0.05)$.

\section{RESULTS}

EAE susceptibility in CEMIB and Botucatu colonies - Susceptibility to EAE development was clearly different in these two colonies. All animals from CEMIB colony developed a standard paralysis, reaching score 4 during the acute phase of the disease (Fig. 1a). As expected from other reports these animals lost around 25\% of their initial weight. Differing from these results, animals from Botucatu colony displayed a very low susceptibility to EAE development. In the experiment showed at Fig. 1b, the animals reached only score 1 (paralysis at the tail tip). In addition, these animals manifested no weight loss, and they even showed a weight gain similar to that observed in the control group. Weight variation in both colonies is documented at Fig. 1d. A diversity of protocols, including the use of increased amounts of myelin or M. butyricum, inoculation by subcutaneous route at the dorsal region and immunization of younger animals were additionally tried. Also, some immunized rats from Botucatu colony were observed during prolonged periods. These strategies were incapable of enhancing EAE development in Lewis rats from this colony.

Differential immune response to myelin in CEMIB and Botucatu colonies - Lymph node cells from immunized CEMIB rats stimulated in vitro with myelin produced significantly higher levels of IFN- $\gamma$, TNF- $\alpha$ and IL-10 (Figs 2a, 2c and 2e, respectively) than cultures 


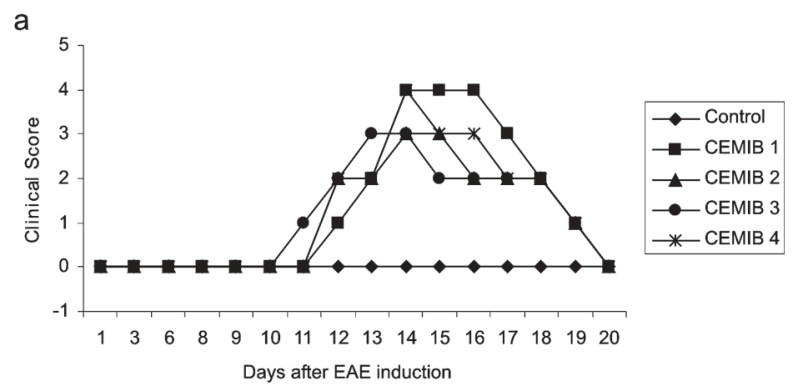

b

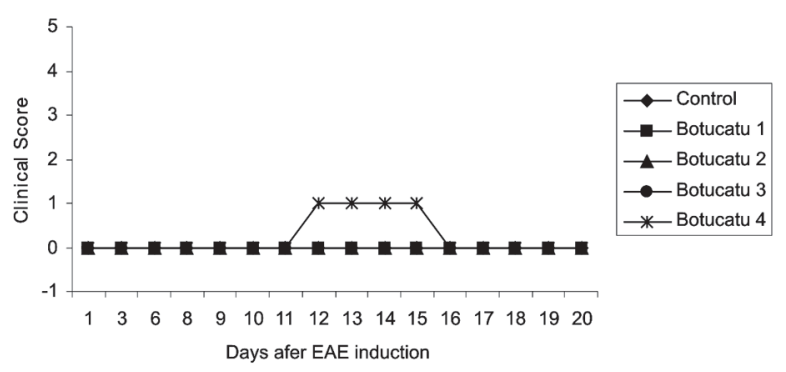

C

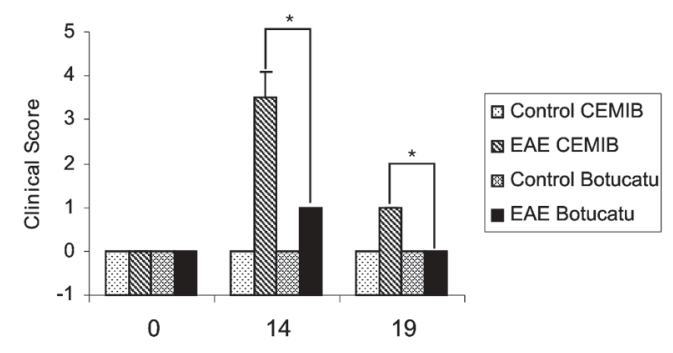

Days after EAE induction

d

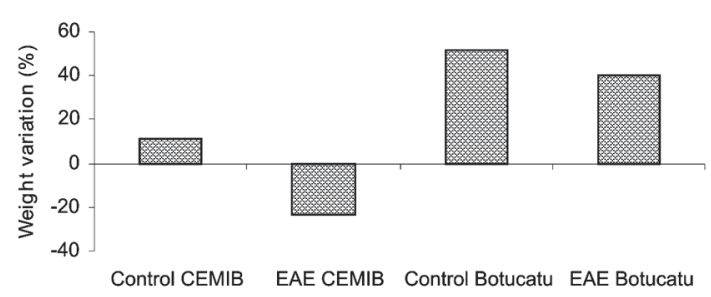

Fig 1: clinical scores and weight variation in two Lewis rat colonies submitted to experimental autoimmune encephalomyelitis (EAE) induction. EAE was induced by subcutaneous injection of myelin plus incomplete Freund adjuvant plus Mycobacterium butyricum in the left footpad clinical scores. a: individual results for CEMIB colony; $b$ : individual results for Botucatu colony; c: comparison of average scores of both colonies at acute and recovery stages; d: weight variation was also daily recorded. This data represents one experiment from three with similar results. Four animals were included in the control group. Asterisks indicate $p<0.05$ in comparison to EAE Botucatu group.

from Botucatu colony. IFN- $\gamma$ production by ConA stimulated cells was similar in both colonies (Fig. 2b), whereas TNF- $\alpha$ and IL-10 induction by ConA were also clearly higher in CEMIB colony (Figs $2 \mathrm{~d}$ and $2 \mathrm{f}$, respectively). Levels of $\operatorname{IgG}_{1}$ (Fig. 3a), but not of $\operatorname{IgG}_{2 b}$ (Fig. 3b) were significantly higher in CEMIB colony.
Histological analysis - Inflammatory infiltrates were observed in the CNS of both colonies but were quantitatively very distinct. Confirming the clinical status observed in CEMIB colony, a clear perivascular mononuclear cell inflammation was observed in the cervical spinal cords of these animals. In contrast, the corresponding neurological tissues from Botucatu colony showed very discrete inflammatory foci. These differences can be observed in Figs 4a (normal rat), 4b (CEMIB EAE rat), and 4c (Botucatu EAE rat).

\section{DISCUSSION}

A very clear difference in susceptibility to EAE development was observed between the two colonies. CEMIB animals colony developed a standard disease, clinically characterized by significant weight loss and high clinical score during the acute phase of the disease. This high susceptibility has frequently been reported by many authors since the early description of EAE in Lewis rats (Swanborg 1975, Stepaniak et al. 1995, Gold et al. 2006). These clinical manifestations were also associated with typical immunological and histopathological signs of EAE development. IFN- $\gamma$ and TNF- $\alpha$ levels whose activity is considered pivotal to both, MS and EAE evolution (Mustafa et al. 1991, Imitola et al. 2005), were significantly elevated in lymph node cell cultures stimulated with myelin. The severity of histologic neural tissue lesions clearly correlated with these clinical symptoms. Cervical spinal cord sections showed typical and abundant inflammatory foci, localized around small vessels, similar to many research reports (Stanislaus et al. 2001). Differing from these results, animals from Botucatu colony immunized in similar conditions, displayed a very low susceptibility to EAE development. These animals presented no weight loss and even showed a weight gain similar to the one observed in the control group. They also showed very low clinical scores characterized by loss of tonicity only at the distal portion of the tail. Other protocols of EAE induction, including the addition of higher amounts of autoantigen, adjuvant and the use of a subcutaneous route of immunization did not change the low clinical scores observed in Botucatu colony. Analysis of the immunological parameters clearly demonstrated that specific anti-myelin response was much more prominent in the CEMIB colony. The finding of a significantly higher production of IFN- $\gamma$ and TNF- $\alpha$ in these animals that developed EAE with high scores is supported by many literature reports that attribute a fundamental role of these cytokines to CNS lesions in both, EAE and MS (Mustafa et al. 1991, Imitola et al. 2005). High IL-10 production by the CEMIB colony was expected and is supported by reports that demonstrate its presence during spontaneous clinical recovery (Diab et al. 1997), and also during immunomodulatory procedures that decrease clinical and histopathological alterations (Stanislaus et al. 2002). However, differently form what was expected, animals form Botucatu colony submitted to EAE induction produced no IL-10 in response to myelin and even produced less IL-10 after ConA stimulation. We cannot, however, exclude other possibilities as production of this cytokine by other kind 
a
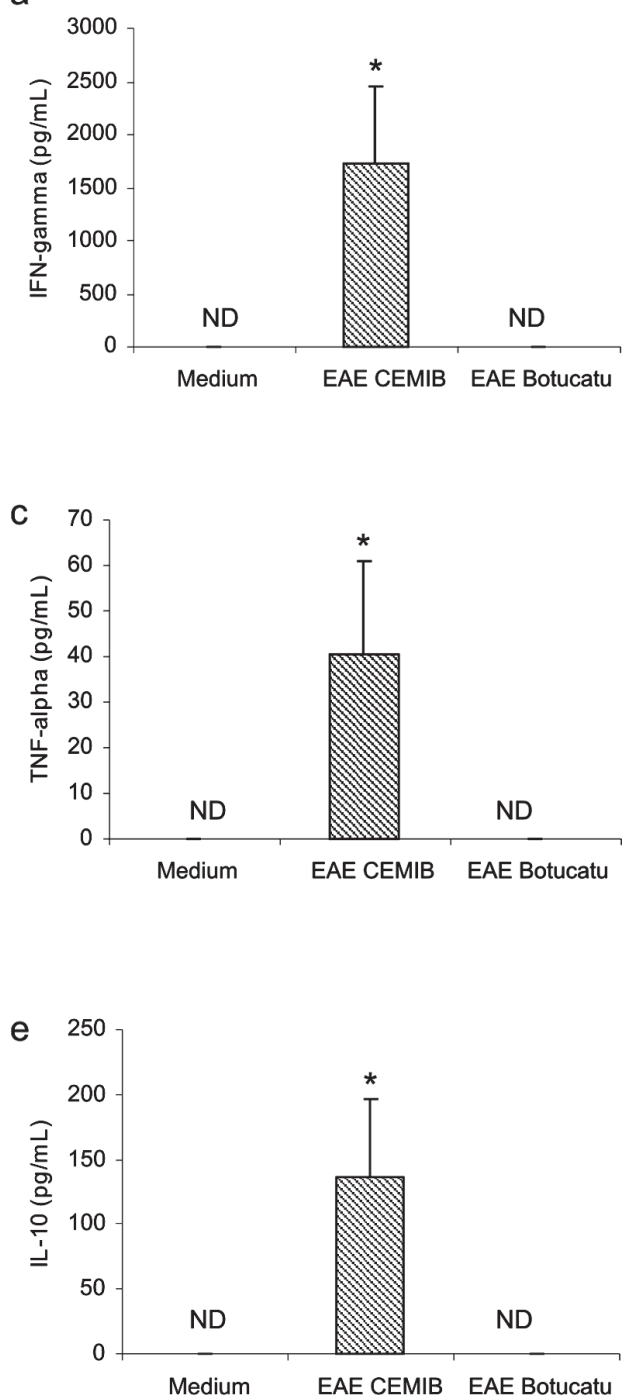

b
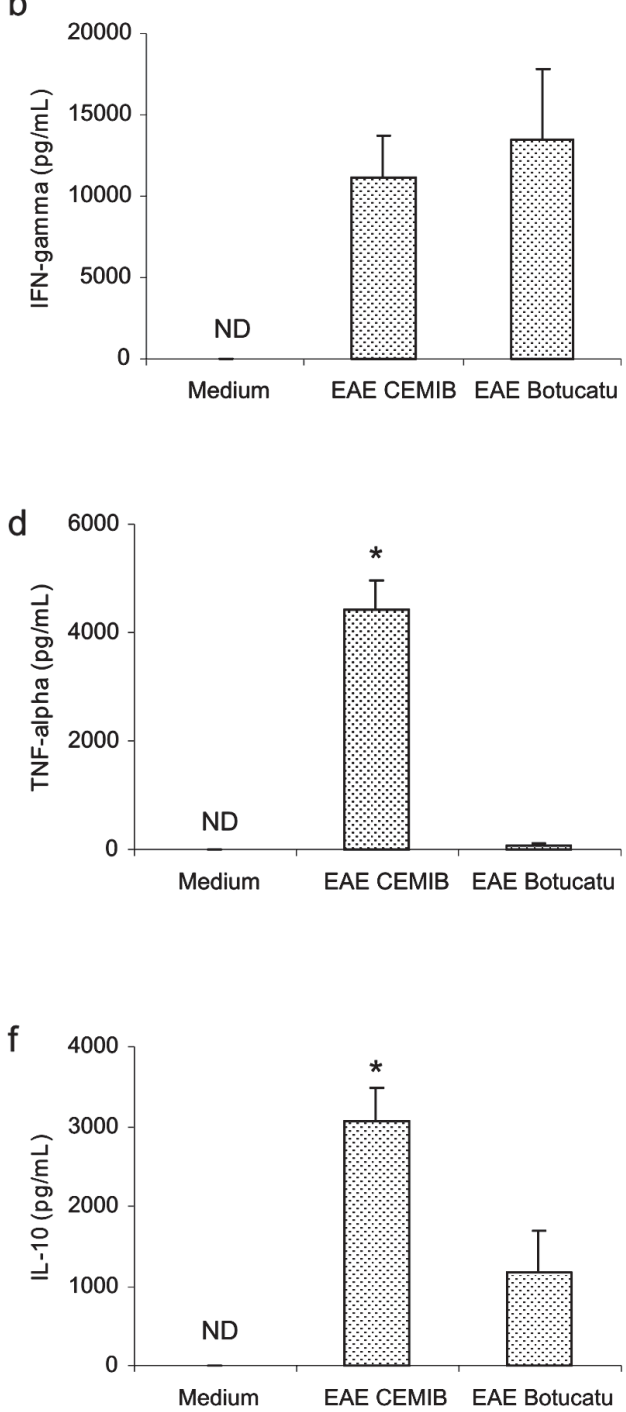

Fig 2: differential specific immune response in immunized CEMIB and Botucatu Lewis rats. Rats were injected with myelin plus incomplete Freund adjuvant plus Mycobacterium butyricum. Twenty days later the animals were euthanized and cytokine production by regional lymph nodes stimulated with myelin (a, c, and e) or ConA (b, d, and f) were determined by ELISA IFN- $\gamma$ (a and b), TNF- $\alpha$ (c and d), IL-10 (e and f). Results represent the geometric mean \pm SEM of four individually tested animals per group. Asterisks indicate $\mathrm{p}<0.05$ in comparison to EAE Botucatu group; ND: not detected.
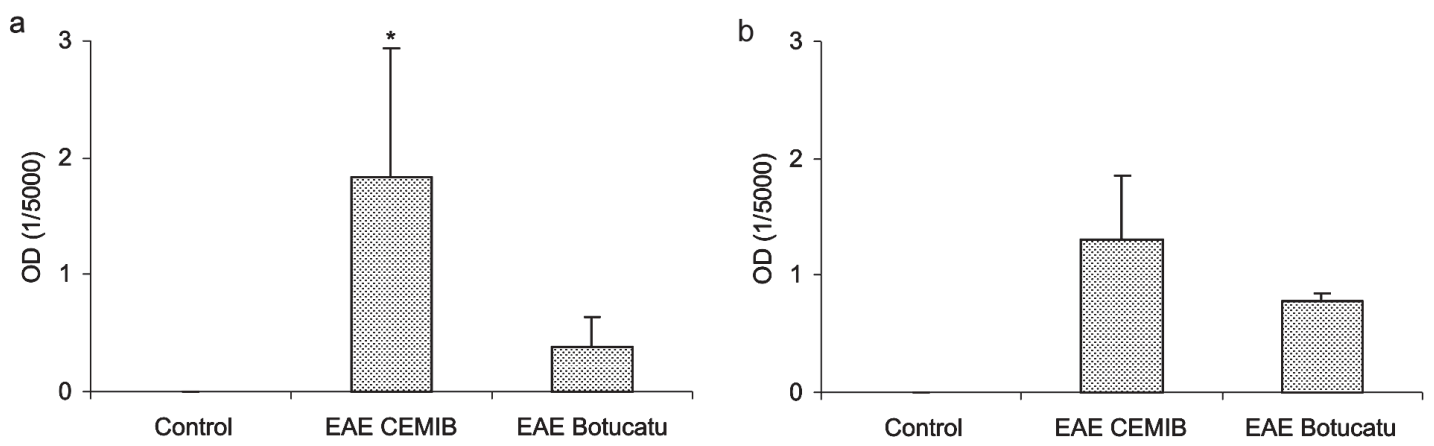

Fig 3: specific antibody production in immunized CEMIB and Botucatu Lewis rats. Rats were injected with myelin plus incomplete Freund adjuvant plus Mycobacterium butyricum. Twenty days later the animals were euthanized and serum anti-myelin antibody levels were determined by ELISA. $\mathrm{a}: \mathrm{IgG}_{1} ; \mathrm{b}: \mathrm{IgG}_{2 \mathrm{~b}}$. Results represent the geometric mean $\pm \mathrm{SEM}$ of four individually tested animals per group. Asterisks indicate $\mathrm{p}<0.05$ in comparison to EAE Botucatu group. 

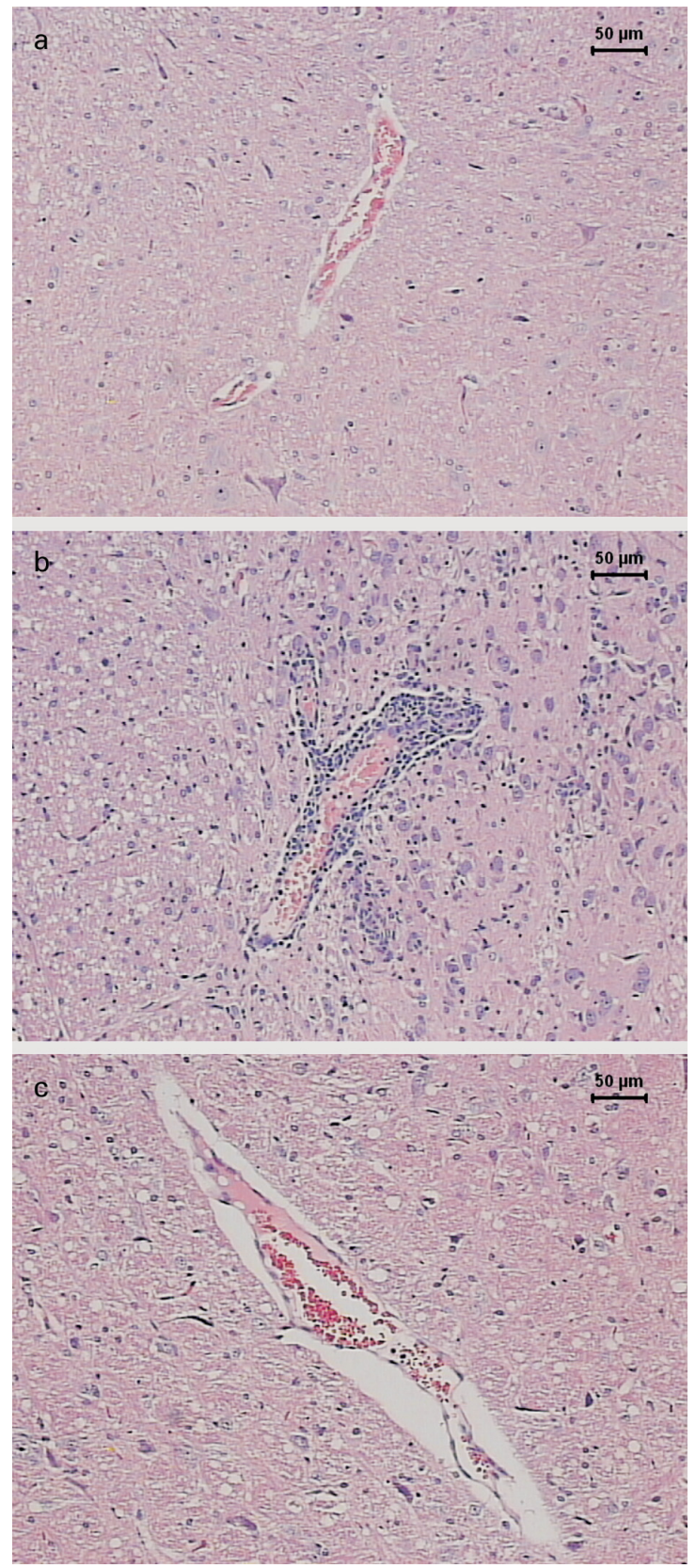

Fig 4: histopathological analysis of spinal cord from Lewis rats with experimental autoimmune encephalomyelitis (EAE). EAE was induced by subcutaneous injection of myelin plus incomplete Freund adjuvant plus Mycobacterium butyricum in the left footpad. Twenty days after the animals were euthanized and cervical spinal cord sections were stained with hematoxylin and eosin and evaluated for extent of inflammatory cell infiltration. a: absence of cellular infiltrates in normal rats; b: typical EAE perivascular inflammatory infiltrates in rats from CEMIB colony; c: very discrete cellular infiltration in rats from Botucatu colony. This analysis refers to one animal from four with very similar results.

of cells as dendritic cells or by cells that migrated to the CNS as has been demonstrated in EAE (Jander et al. 1998, Yang et al. 2000). Additionally, the contribution of other cytokines as TGF- $\beta$ that is described as an important endogenous mechanism to limit the extension of inflammation cannot be ruled out (Tanuma et al. 1997). In this context, our data could suggest that disease resistance may be a result of an immunologic deficit, maybe triggered by a regulatory $\mathrm{T}$ cell (Treg cell). Contribution of Treg cells to initiate remission phase in experimental EAE and its deficiency in clinical MS manifestations have been reported (Viglietta et al. 2004, Mann et al. 2007). Therefore, a very appealing explanation for this striking difference could be the differential sanitation condition used to raise and keep these two colonies. This possibility is based on a growing body of evidence suggesting that excessive hygiene conditions could contribute to the increased incidence of allergic and autoimmune diseases in developed countries. This idea has been named "hygiene hypothesis" and has been supported by investigations in epidemiology (Cooke et al. 2004), basic immunology (Vercelli 2006), animal models (Kitagaki et al. 2006), and human trials with probiotic agents (Floch $\&$ Monrrose 2005). A prominent theme emerging from this research has been the discovery of a relative deficiency of T-regulatory cell activity in allergy and autoimmunity (Randolph \& Fathman 2006). Additionally, in some animal models, restitution of T-regulatory cell activity has been achieved by exposure to infectious agents such as helminths or products derived from them (Wilson et al. 2005). The relevance of hygiene hypothesis to EAE and MS has been scientifically supported by both experimental approaches and epidemiological studies in MS population. For example, in a murine EAE model, it was demonstrated that the infection with Schistosoma mansoni delayed the onset of the disease and also prevented inflammation in the CNS (La Flamme et al. 2003, 2004, Sewell et al. 2003). Epidemiological investigation revealed a dichotomous relationship between the global distribution of MS and parasitic infections (Fleming \& Cook 2006). Also, longitudinal and migratory studies of MS have been consistent with the hygiene hypothesis, showing a paralleled increase in MS and improved sanitation (Cabre et al. 2005). In this context we evaluated the presence of worm eggs in the feces and adult worms in the intestine of Lewis rats from both colonies. Interestingly, a high amount of eggs from Aspiculuris sp. and Syphacia sp. were found in Botucatu animals, but not in CEMIB ones.

In light of recent reports that demonstrated or suggested a protective effect of Schistosoma infections in MS or EAE, these results support the view that this natural rodent infection could protect these animals from developing EAE. The possibility that a helmintic infection can block EAE development in Lewis rats from CEMIB colony is being investigated in our laboratory. This approach will allow us to establish the contribution of the infection and also of Treg cells to EAE resistance as has been demonstrated for allergic airway inflammation (Wilson et al. 2005).

Even though we believe that our findings and the epidemiological evidences suggest a strong correlation with the hygiene hypothesis, we cannot exclude the possibility of a genetic diversion in these animals. Genetic mutations involving, for example, nitric oxide synthase and regulatory cytokines, which have been described as relevant factors for EAE development, could contribute to this resistance (Cautain et al. 2001, Staykova et al. 2005). 


\section{REFERENCES}

Cabre P, Signate A, Olindo S, Caparros-Lefebvre D, Bera O, Smadja D 2005. Role of return migration in the emergence of multiple sclerosis in the French West Indies. Brain 128: 2899-2910.

Cautain B, Damoiseaux J, Bernard I, van Straaten H, van Breda Vriesman P, Boneu B, Druet P, Saoudi A 2001. Essential role of TGF-beta in the natural resistance to experimental allergic encephalomyelitis in rats. Eur J Immunol 31: 1132-1140.

Cooke A, Zaccone P, Raine T, Phillips JM, Dunne DW 2004. Infection and autoimmunity: are we winning the war, only to lose the peace? Trends Parasitol 20: 316-321.

Diab A, Zhu J, Xiao BG, Mustafa M, Link H 1997. High IL-6 and low IL-10 in the central nervous system are associated with protracted relapsing EAE in DA rats. $J$ Neuropathol Exp Neurol 56: 641-650.

Ditamo Y, Degano AL, Maccio DR, Pistoresi-Palencia MC, Roth GA 2005. Age-related changes in the development of experimental autoimmune encephalomyelitis. Immunol Cell Biol 83: 75-82.

Fleming JO, Cook TD 2006. Multiple sclerosis and the hygiene hypothesis. Neurology 67: 2085-2086.

Floch MH, Monrrose DC 2005. Use of probiotics in humans: an analysis of the literature. Gastroenterol Clin North Am 34: 547-570.

Gold R, Linington C, Lassmann H 2006. Understanding pathogenesis and therapy of multiple sclerosis via animal models: 70 years of merits and culprits in experimental encephalomyelitis research. Brain 129: 1953-1971.

Imitola J, Chitnis T, Khoury SJ 2005. Cytokines in multiple sclerosis: from bench to bedside. Pharmacol Ther 106: 163-177.

Jander S, Pohl J, D’Urso D, Gillen C, Stoll G 1998. Time course and cellular localization of interleukin-10 mRNA and protein expression in autoimmune inflammation of the rat central nervous system. Am J Pathol 152: 975-982.

Kitagaki K, Businga TR, Racila D, Ellitott DE, Weinstock JV, Kline JN 2006. Intestinal helminths protect in a murine model of asthma. J Immunol 177: 1628-1635.

La Flamme AC, Canagasabey K, Harvie M, Bäckström BT 2004. Schistosomiasis protects against multiple sclerosis. Mem Inst Oswaldo Cruz 99: 33-36.

La Flamme AC, Ruddenklau K, Bäckström BT 2003. Schistosomiasis decreases central nervous system inflammation and alters the progression of experimental autoimmune encephalomyelitis. Infect Immunol 71: 4996-5004.

Mann MK, Maresz K, Shriver LP, Tan Y, Dittel BN 2007. B cell regulation of CD4+CD25+ T regulatory cells and IL-10 via B7 is essential for recovery from experimental autoimmune encephalomyelitis. J Immunol 178: 3447-3456.

Mustafa MI, Diener P, Höjeberg B, Van der Meide P, Olsson T 1991. T cell immunity and interferon-g secretion during experimental allergic encephalomyelitis in Lewis rats. $J$ Neuroimmunol 31: 165-177.

Papenfuss TL, Rogers CJ, Gienapp I, Yurrita M, McClain M, Damico N, Valo J, Song F, Whitacre CC 2004. Sex difference in experimental autoimmune encephalomyelitis in multiple murine strains. J Neuroimmunol 150: 59-69.
Randolph DA, Fathman CG 2006. CD4+CD25+ regulatory T cells and their therapeutic potential. Annu Rev Med 57: 381-402.

Sewell DL, Qing Z, Reinke EK, Elliott D, Weinstock J, Hogan LH, Sandor M, Fabry Z 2003. Immunomodulation of experimental autoimmune encephalomyelitis by helminth ova immunization. Int Immunol 15: 59-69.

Sewell DL, Reinke EK, Hogan LH, Sandor M, Fabry Z 2002. Immunoregulation of CNS autoimmunity by helminth and mycobacterial infections. Immunol Lett 82: 101-110.

Sotgiu S, Pugliatti M, Fois ML, Arru G, Sanna A, Sotgiu MA, Rosati G 2004. Genes, environment, and susceptibility to multiple sclerosis. Neurobiol Dis 17: 131-143.

Stanislaus R, Gilg AG, Singh AK, Singh I 2002. Immunomodulation of experimental autoimmune encephalomyelitis in the Lewis rats by Lovastatin. Neurosci Lett 333: 167-170.

Stanislaus R, Singh AK, Singh I 2001. Lovastatin treatment decreases mononuclear cell infiltration into the CNS of Lewis rats with experimental allergic encephalomyelitis. JNeurosci Res 66: 155-162.

Staykova MA, Paridaen JT, Cowden WB, Willenborg DO 2005. Nitric oxide contributes to resistance of the Brown Norway rat to experimental autoimmune encephalomyelitis. Am J Pathol 166: 147-157.

Stepaniak JA, Gould KE, Sun D, Swanborg RH 1995. A comparative study of experimental autoimmune encephalomyelitis in Lewis and DA rats. J Immunol 155: 2762-2769.

Swanborg RH 1975. Antigen-induced inhibition of experimental allergic encephalomyelitis. IV. Studies of the C-terminal end of the myelin basic protein molecule (1). Immunol Commun 4: 387-397.

Swanborg RH 1988. Experimental allergic encephalomyelitis. Methods Enzymol 162: 413-421.

Swanborg RH 1995. Experimental autoimmune encephalomyelitis in rodents as a model for human demyelination disease. Clin Immunol Immunopathol 77: 4-13.

Swanborg RH 2001. Experimental autoimmune encephalomyelitis in the rat: lessons in T-cell immunology and autoreactivity. Immunol Rev 184: 129-135.

Tanuma N, Kojima T, Shin T, Aikawa Y, Kohji T, Ishihara Y, Matsumoto Y 1997. Competitive PCR quantification of proand anti-inflammatory cytokine mRNA in the central nervous system during autoimmune encephalomyelitis. $J$ Neuroimmunol 73: 197-206.

Vercelli D 2006. Mechanisms of the hygiene hypothesis-molecular and otherwise. Curr Opin Immunol 18: 733-737.

Viglietta V, Baecher-Allan C, Weiner HL, Hafler DA 2004. Loss of functional suppression by CD4+CD25+ regulatory T cells in patients with multiple sclerosis. J Exp Med 199: 971-979.

Wilson MS, Taylor MD, Balic A, Finney CA, Lamb JR, Maizels RM 2005. Suppression of allergic airway inflammation by helminth-induced regulatory T cells. J Exp Med 202: 1199-1212.

Yang JS, Xu LY, Huang YM, Van Der Meide PH, Link H, Xiao BG 2000. Adherent dendritic cells expressing high levels of interleukin-10 and low levels of interleukin-12 induce antigen-specific tolerance to experimental autoimmune encephalomyelitis. Immunology 101: 397-403. 